\title{
A Versatile Digitally Programmable Voltage Mode Multifunctional Biquadratic Filter
}

\author{
Bilal Arif \\ Department of Electronics \\ Engineering \\ Aligarh Muslim University \\ Aligarh, India
}

\author{
Mohd. Usama Ismail \\ Department of Electronics \\ Engineering \\ Aligarh Muslim University \\ Aligarh, India
}

\author{
Ale Imran \\ Department of Electronics \\ Engineering \\ Aligarh Muslim University \\ Aligarh, India
}

\begin{abstract}
In this paper, a digitally controlled single input multi-output voltage mode multifunctional biquadratic filter is presented. The circuit makes use of only a single DVCC, two grounded capacitors, one grounded and two floating resistors. The digital control is incorporated using a current-summing network (CSN). Tuning of cut-off frequency is carried out with the help of a 3-bit digital control word. PSPICE simulations using TSMC 0.25 micron CMOS technology have been performed to validate the theoretically predicted results.
\end{abstract}

\section{General Terms}

Analog Signal Processing, Active Filters

\section{Keywords}

Current-mode; Voltage-mode; Differential Voltage Current Conveyor (DVCC); multifunctional filter; digitally controlled circuits; cut off frequency; single input multi output (S.I.M.O).

\section{INTRODUCTION}

Lately the world has observed the emergence of the current mode circuits as new and more efficient analog building blocks owing to the various advantages they have over the conventional voltage mode circuits, like wider bandwidth, greater linearity, higher slew-rate, better dynamic range, simple circuitry and low power consumption [1]. Resulting in inception of new current-mode active building blocks such as operational transconductance amplifiers, current-feedback opamps (CFOA), second generation current conveyors (CCII), four terminal floating nullors (FTFN), differential voltage current conveyor (DVCC), differential difference current conveyor (DDCC), third-generation current-conveyor (CCIII), dual $\mathrm{X}$ current conveyors (DXCCII), current controlled current conveyors (CCCII) [2].

Instrumentation, analog signal processing, automatic control and communication are the application areas for current-mode circuits. Realization of the current mode filters and oscillators is the most significant of these applications [3].

CCII (second generation current conveyor) has become very popular and is very useful [4]. But it has its own limitations such as it cannot provide differential or floating inputs and also has only single high input impedance terminal.

Considering drawbacks of CCII block new analog building blocks were introduced which include differential difference current conveyor (DDCC) [5] another building block introduced was differential voltage current conveyor (DVCC) which is slight modified version of DDCC block having its $\mathrm{Y}_{3}$ terminal grounded [6]. DVCC is a very useful analog building block whose applications have been thoroughly worked upon and could be studied in the existing literature. [7-10]

In this paper, the filter circuit proposed in [11] by Hua-Pin Chen, Wei Chen and Guo-Wei Huang employs a single DVCC, two grounded capacitors and three resistors is used to design and implement a digitally controlled S.I.M.O. voltagemode multifunctional biquadratic filter.

Simultaneous realization of lowpass, bandpass and highpass responses increases the utilization of the filter circuit reduces its overall cost Use of grounded capacitors increases the circuit's suitability for integration as grounded capacitors can compensate for the stray capacitances at the nodes. PSPICE simulations of the CMOS based controlled multifunctional filter are performed to demonstrate results.

\section{DVCC}

As shown in Fig. 1, the DVCC is a five-terminal active analog building block with terminal characteristics described by the following matrix equation [12].

$$
\left(\begin{array}{c}
I_{Y 1} \\
I_{Y 2} \\
V_{X} \\
I_{Z+} \\
I_{Z-}
\end{array}\right)=\left(\begin{array}{ccccc}
0 & 0 & 0 & 0 & 0 \\
0 & 0 & 0 & 0 & 0 \\
1 & -1 & 0 & 0 & 0 \\
0 & 0 & 1 & 0 & 0 \\
0 & 0 & -1 & 0 & 0
\end{array}\right)\left(\begin{array}{l}
V_{Y 1} \\
V_{Y 2} \\
I_{X} \\
V_{Z+} \\
V_{Z-}
\end{array}\right)
$$

An ideal DVCC has very low (almost zero) input resistance at terminal $\mathrm{X}$, and quite large (infinite) resistance at the two $\mathrm{Y}$ terminals as well as the $\mathrm{Z}$ terminal. The output current follows the flow direction of the input current with both currents flowing either into or out of the device. The CMOS implementation of DVCC is as shown in Fig. 2. The MOS transistors used are matched and 0.25 micron technology has been used. 


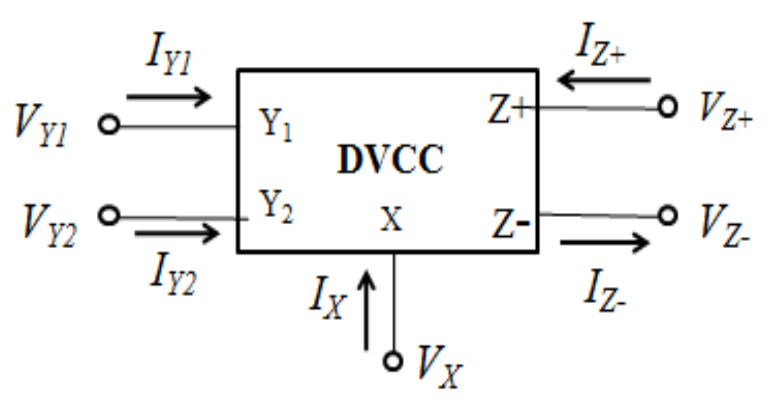

Fig 1: Symbol representing the dual output DVCC

\section{IMPLEMENTATION OF THE DVCC FILTER}

The implemented voltage-mode multifunctional filter [11] is illustrated in Fig. 3. The analysis of the circuit provides us with the following equations (2), (3) and (4), these equations are lowpass, bandpass and highpass filter transfer functions respectively.

$$
\begin{aligned}
& \frac{V_{01}}{V_{I N}}=\frac{\frac{1}{R_{1} R_{2} C_{1} C_{2}}}{s^{2}+s\left(\frac{1}{R_{1} C_{2}}+\frac{1}{R_{2} C_{2}}\right)+\frac{1}{R_{1} R_{2} C_{1} C_{2}}} \\
& \frac{V_{02}}{V_{I N}}=\frac{(-s) \frac{1}{R_{1} C_{2}}}{s^{2}+s\left(\frac{1}{R_{1} C_{2}}+\frac{1}{R_{2} C_{2}}\right)+\frac{1}{R_{1} R_{2} C_{1} C_{2}}} \\
& \frac{V_{03}}{V_{I N}}=\frac{r s^{2}}{s^{2}+s\left(\frac{1}{R_{1} C_{2}}+\frac{1}{R_{2} C_{2}}\right)+\frac{1}{R_{1} R_{2} C_{1} C_{2}}}
\end{aligned}
$$

$$
\text { where } r=\frac{R_{3}}{R_{1}}
$$

The resonant angular frequency $\omega \mathrm{o}$, and the quality factor, $\mathrm{Q}$, are given by:

$$
\begin{gathered}
\omega \mathrm{O}=\frac{1}{\sqrt{\mathrm{R}_{1} \mathrm{R}_{2} \mathrm{C}_{1} \mathrm{C}_{2}}} \\
\mathrm{Q}=\frac{\sqrt{R_{1} R_{2} C_{1} C_{2}}}{R_{1} C_{1}+R_{2} C_{1}}
\end{gathered}
$$

Equation 6 clearly indicates that the change in cut-off frequency can be done only if passive component are change. Hence the limitation of this circuit is that for a given set of passive elements the circuit can work for only a particular cut-off frequency. In the next section a block DC-DVCC is discussed which eliminates this limitation and the frequency of this circuit could be digitally controlled.

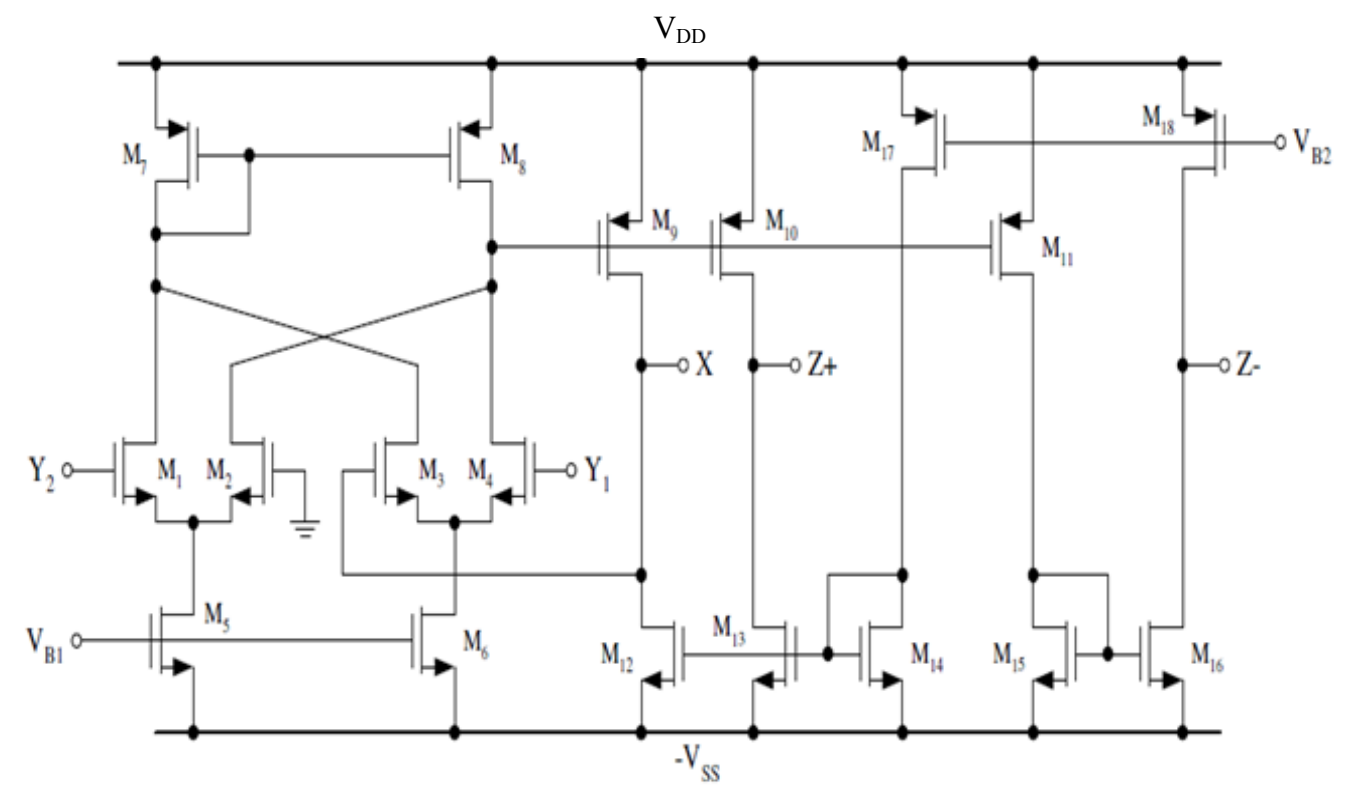

Fig 2: CMOS realization of the dual output DVCC [12] 


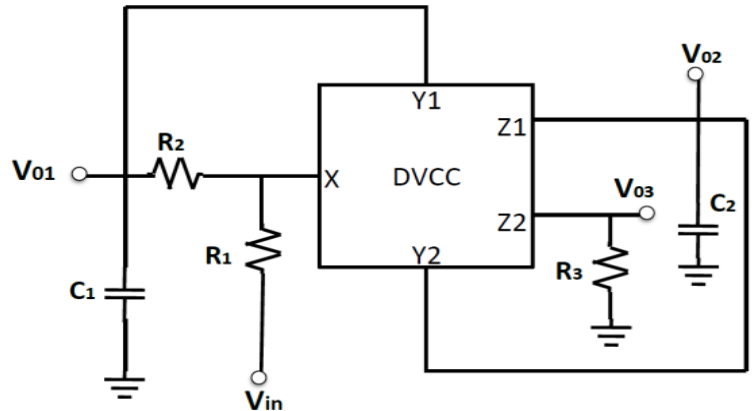

Fig 3: Circuit diagram of the multifunction biquadratic filter [11]

We can see that lowpass, bandpass and highpass functions can be simultaneously realized without changing the circuit configuration. Also, for $\mathrm{R}_{1}=\mathrm{R}_{3}$, by adding lowpass and highpass outputs, the transfer function can be re-organized to give a band reject filter transfer function as follows:

$\frac{V_{B R}}{V_{I N}}=\frac{V_{03}+V_{01}}{V_{I N}}=\frac{r s^{2}+\frac{1}{R_{1} R_{2} C_{1} C_{2}}}{s^{2}+s\left(\frac{1}{R_{1} C_{2}}+\frac{1}{R_{2} C_{2}}\right)+\frac{1}{R_{1} R_{2} C_{1} C_{2}}}$

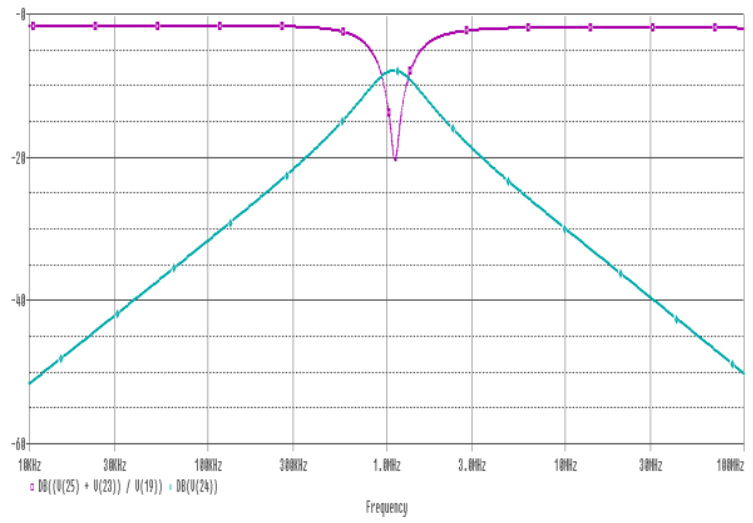

Fig. 4(a). Simulated Bandpass and Bandreject responses

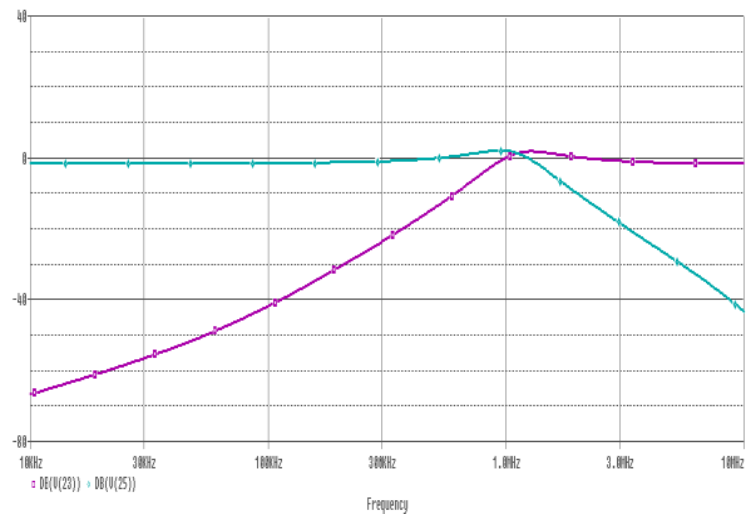

Fig.4(b): Simulated Lowpass and Highpass responses
Table 1. Aspect ratios of the cmos transistors of the DVCC [12]

\begin{tabular}{|c|c|c|}
\hline Transistors & $\mathbf{W}(\boldsymbol{\mu m})$ & $\mathbf{L}(\boldsymbol{\mu m})$ \\
\hline $\mathbf{M}_{\mathbf{1}}-\mathbf{M}_{\mathbf{4}}$ & 1 & 0.8 \\
\hline $\mathbf{M}_{\mathbf{5}}-\mathbf{M}_{\mathbf{6}}$ & 24.2 & 0.8 \\
\hline $\mathbf{M}_{\mathbf{7}}-\mathbf{M}_{\mathbf{8}}$ & 6.8 & 0.8 \\
\hline $\mathbf{M}_{\mathbf{9}}-\mathbf{M}_{\mathbf{1 1}}, \mathbf{M}_{\mathbf{1 7}}$ & 18.6 & 0.6 \\
\hline $\mathbf{M}_{\mathbf{1 2}}-\mathbf{M}_{\mathbf{1 4}}$ & 25 & 0.8 \\
\hline $\mathbf{M}_{\mathbf{1 5}}$ & 19.6 & 0.8 \\
\hline $\mathbf{M}_{\mathbf{1 6}}$ & 18 & 0.8 \\
\hline $\mathbf{M}_{\mathbf{1 8}}$ & 20 & 0.6 \\
\hline
\end{tabular}

In simulations, using PSPICE DVCC was realized by the CMOS implementation illustrated in Fig. 2 using TSMC $0.25-\mu \mathrm{m}$ process parameters. The aspect ratios of the CMOS transistors used for implementing DVCC are presented in Table 1 . The supply voltages were given value $\mathrm{V}_{\mathrm{DD}}=-\mathrm{V}_{\mathrm{SS}}=2$ $\mathrm{V}$ and the biasing voltages were assigned as $\mathrm{V}_{\mathrm{B} 1}=-1.32 \mathrm{~V}$ and $\mathrm{V}_{\mathrm{B} 2}=+0.7 \mathrm{~V}$. The circuit was designed for fo $=\omega \mathrm{o} / 2 \pi=1 \mathrm{MHz}$ and $\mathrm{Q}=1.58$ by choosing $\mathrm{R}_{1}=\mathrm{R}_{2}=\mathrm{R}_{3}=10 \mathrm{k} \Omega$ and $\mathrm{C}_{1}=5 \mathrm{pF}, \mathrm{C}_{2}=50 \mathrm{pF}$. The responses of the multifunctional filter for the above configuration are shown in Fig. 4(a) and (b). The results agree with the theoretical analysis.

\section{DC- DVCC}

To introduce the controllability in the multifunctional filter we have used a digitally controlled DVCC (DC-DVCC) shown in Fig. 5. The modified terminal characteristics for the same are as follows:

$$
\left(\begin{array}{l}
I_{Y 1} \\
I_{Y Z} \\
V_{X} \\
I_{Z+} \\
I_{Z}
\end{array}\right)=\left(\begin{array}{ccccc}
0 & 0 & 0 & 0 & 0 \\
0 & 0 & 0 & 0 & 0 \\
1 & -1 & 0 & 0 & 0 \\
0 & 0 & k & 0 & 0 \\
0 & 0 & -k & 0 & 0
\end{array}\right)\left(\begin{array}{l}
V_{Y 1} \\
V_{Y Z} \\
I_{X} \\
V_{Z+} \\
V_{Z}
\end{array}\right)
$$

Where: $\quad \mathrm{k}=\frac{\mathrm{I}_{\mathrm{Z}}}{\mathrm{I}_{\mathrm{X}}}$

For obtaining the digital control in the DVCC current summing networks (CSNs) are employed at the Z (Z+ and Z-) terminals for controlling the current transfer gain parameter $\mathrm{k}$. A variation from 1 to $\left(2^{\mathrm{n}}-1\right)$ is observed in the gain parameter $\mathrm{k}$, where $\mathrm{n}$ signifies the number of transistor arrays. The modified circuit of DVCC with the transistors arrays is as shown in Fig.5. The CSN consists n transistor pairs, the aspect ratios of whose PMOS and NMOS transistors respectively are given by: 


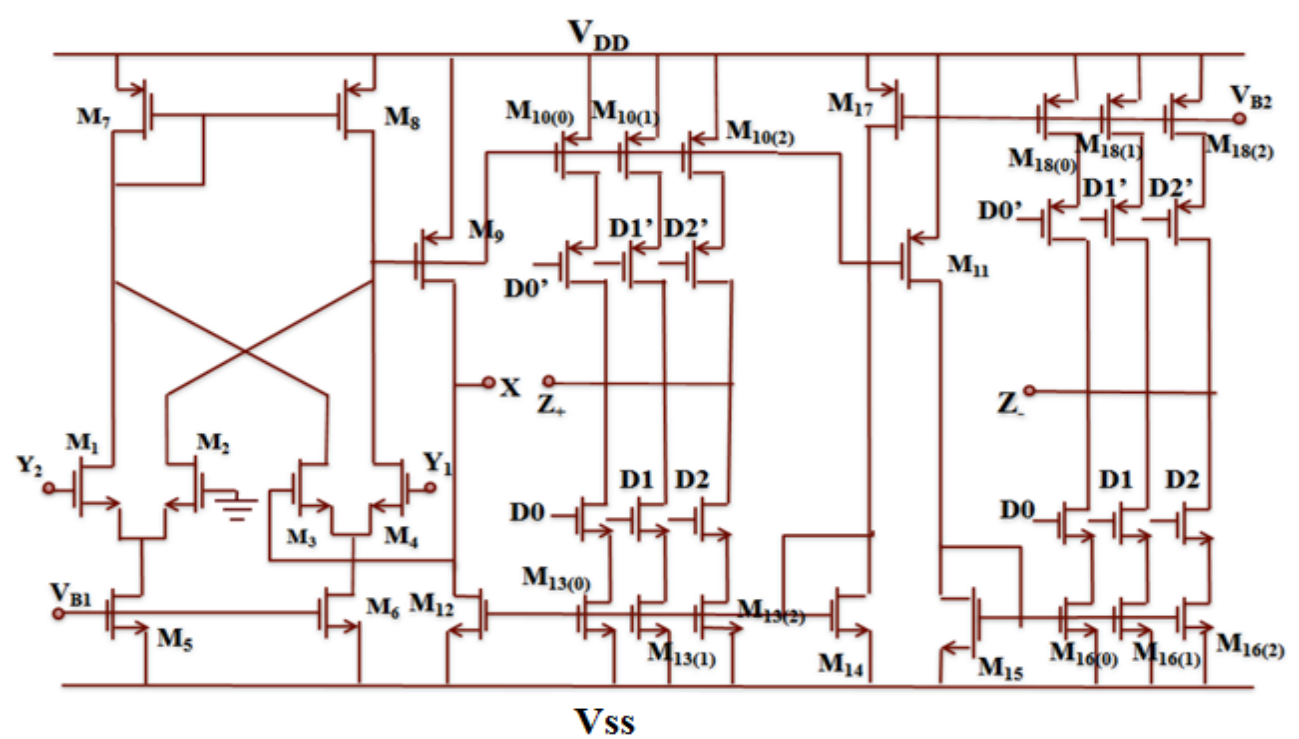

Fig.5: CMOS realization of the digitally programmable DVCC with gain $k$

$$
\begin{aligned}
& \left(\frac{W}{L}\right)_{i}=2^{i}\left(\frac{W}{L}\right)_{9} \\
& \left(\frac{W}{L}\right)_{i}=2^{i}\left(\frac{W}{L}\right)_{12}
\end{aligned}
$$

The current at the $\mathrm{Z}$ terminal is assumed to be flowing out of the DC-DVCC and can be expressed by:

$$
I_{Z}=\sum_{i=0}^{n-1} d_{i} 2^{i}\left(I_{9}-I_{12}\right)
$$

Therefore, the proposed DC-DVCC provides a current transfer gain, $\mathrm{k}$ equal to:

$k=\frac{I_{Z}}{I_{X}}=\frac{\sum_{i=0}^{n-1} d_{i} 2^{i}\left(I_{9}-I_{12}\right)}{\left(I_{9}-I_{12}\right)}=\sum_{i=0}^{n-1} d_{i} 2^{i}$

Where $d_{i}$ are the bits applied to the i-th branch in the CSN. Now the current flow in a particular branch is enabled or disabled depending upon whether $d_{i}$ is a logic 1 or logic 0 [13].

\section{DIGITALLY CONTROLLED S.I.M.O. \\ FILTER}

In this section the proposed digitally controlled voltage-mode multifunctional biquadratic filter is presented as shown in Fig. 6. The introduction of the DC-DVCC comprising of CSN modifies the expression of pole-frequency $\omega_{0}$ of the multifunctional filter. The expressions for the digitally controlled filter responses can now be expressed as:

$$
\frac{V_{01}}{V_{I N}}=\frac{\frac{k}{R_{1} R_{2} C_{1} C_{2}}}{s^{2}+k s\left(\frac{1}{R_{1} C_{2}}+\frac{1}{R_{2} C_{2}}\right)+\frac{k}{R_{1} R_{2} C_{1} C_{2}}}
$$

$$
\begin{aligned}
& \frac{V_{02}}{V_{I N}}=\frac{(-s k) \frac{1}{R_{1} C_{2}}}{s^{2}+k s\left(\frac{1}{R_{1} C_{2}}+\frac{1}{R_{2} C_{2}}\right)+\frac{k}{R_{1} R_{2} C_{1} C_{2}}} \\
& \frac{V_{03}}{V_{I N}}=\frac{r k s^{2}}{s^{2}+k s\left(\frac{1}{R_{1} C_{2}}+\frac{1}{R_{2} C_{2}}\right)+\frac{k}{R_{1} R_{2} C_{1} C_{2}}}
\end{aligned}
$$$$
\text { where } \mathrm{k}=\frac{\mathrm{I}_{\mathrm{Z}}}{\mathrm{I}_{\mathrm{X}}} \text { and } \mathrm{r}=\frac{\mathrm{R}_{3}}{\mathrm{R}_{1}}
$$

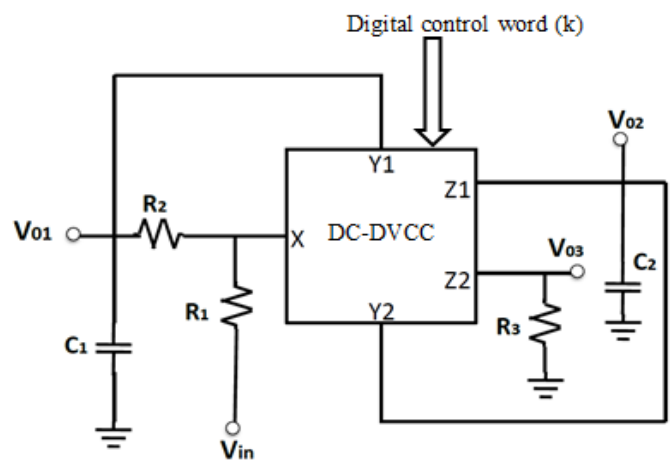

Fig.7: Proposed Digitally controlled voltage-mode multi-function biquadratic filter

Cutoff frequency $\left(\omega_{0}\right)$ and quality factor $(\mathrm{Q})$ of the controlled filter can be expressed as:

$$
\begin{gathered}
\omega 0=\frac{\sqrt{k}}{\sqrt{\mathrm{R}_{1} \mathrm{R}_{2} \mathrm{C}_{1} \mathrm{C}_{2}}} \\
Q=\frac{1}{\sqrt{k}} \frac{\sqrt{R_{1} R_{2} C_{1} C_{2}}}{R_{1} C_{1}+R_{2} C_{1}}
\end{gathered}
$$




\section{SIMULATION RESULTS}

The proposed digitally controlled multifunctional biquadratic filter circuit in Fig. 6 has been simulated and all the results are verified with PSPICE. Fig.7, 8 and 9 are the simulated responses obtained for the low-pass, high pass, and band-pass filters respectively keeping the digital control word $\left[\begin{array}{lll}\mathrm{d}_{2} & \mathrm{~d}_{1} & \mathrm{~d}_{0}\end{array}\right]=\left[\begin{array}{lll}0 & 1 & 0\end{array}\right]$ and $\left[\begin{array}{lll}1 & 0 & 1\end{array}\right]$. The 3-bit digital control word is varied from [lll $\left.\begin{array}{ll}0 & 0\end{array}\right]$ to $[111]$ to obtain the variation in the cut off frequency of the multifunction filter. Figures 10 (a), (b) and (c) are the plots showing the variation in the cut off frequency with the control word.

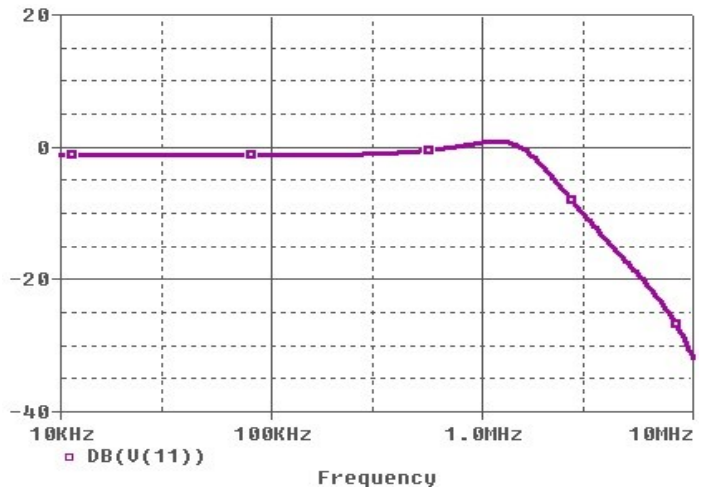

Fig. 7(a): Simulated magnitude response (in $\mathrm{dB}$ ) for low

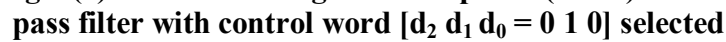

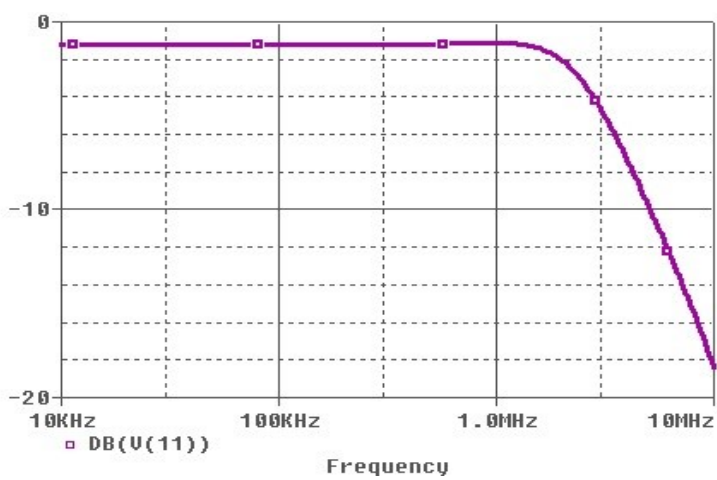

Fig. 7(b): Simulated magnitude response (in $\mathrm{dB}$ ) for lowpass filter with $k\left[\begin{array}{lll}d_{2} & d_{1} & d_{0}= \\ 0 & 0 & 1\end{array}\right]$

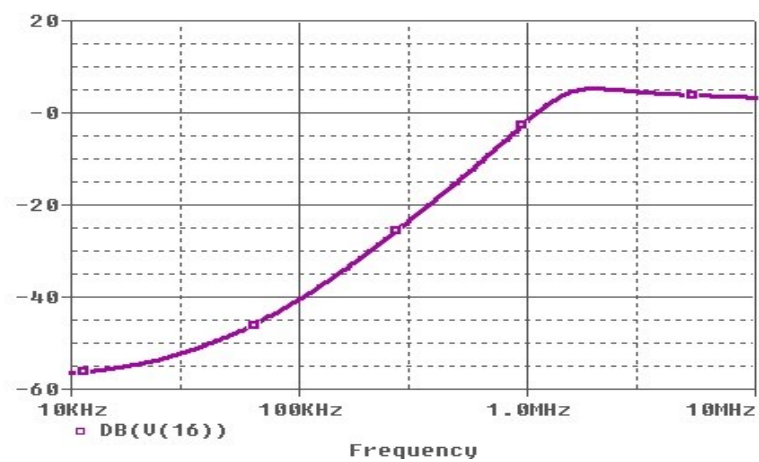

Fig. 8(a): Simulated magnitude response (in $\mathrm{dB}$ ) for high



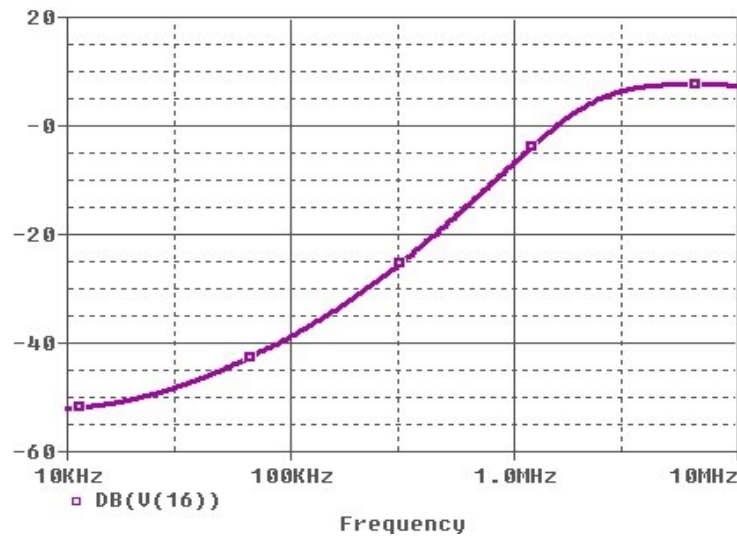

Fig. 8(b): Simulated magnitude response (in $\mathrm{dB}$ ) for high pass filter with control word $\left[d_{2} d_{1} d_{0}=\begin{array}{lll}1 & 0 & 1\end{array}\right]$ selected

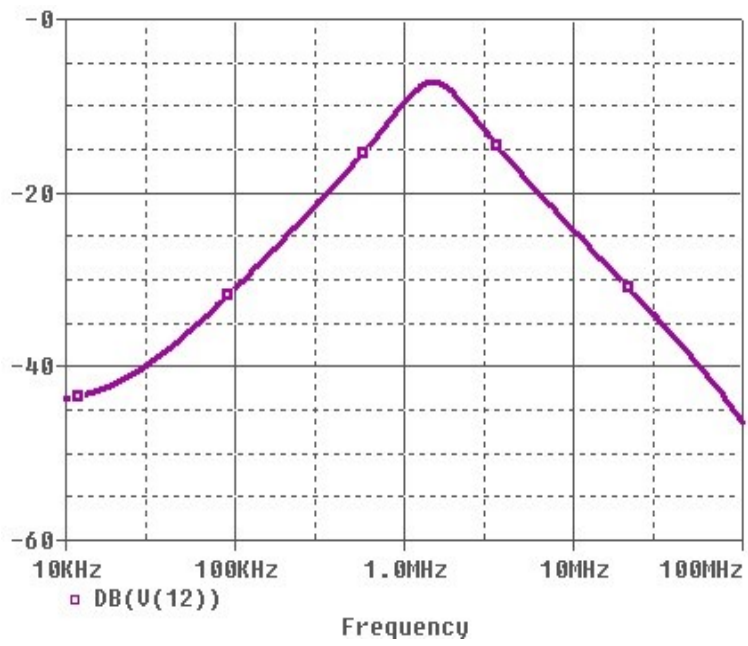

Fig. 9(a): Simulated magnitude response (in $\mathrm{dB}$ ) for band

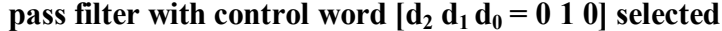

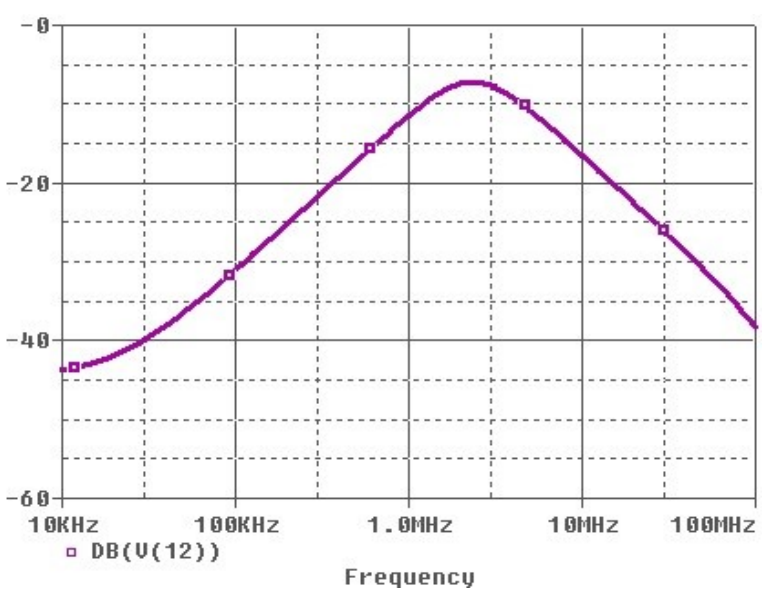

Fig. 9(b): Simulated magnitude response (in $\mathrm{dB}$ ) for band

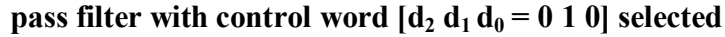




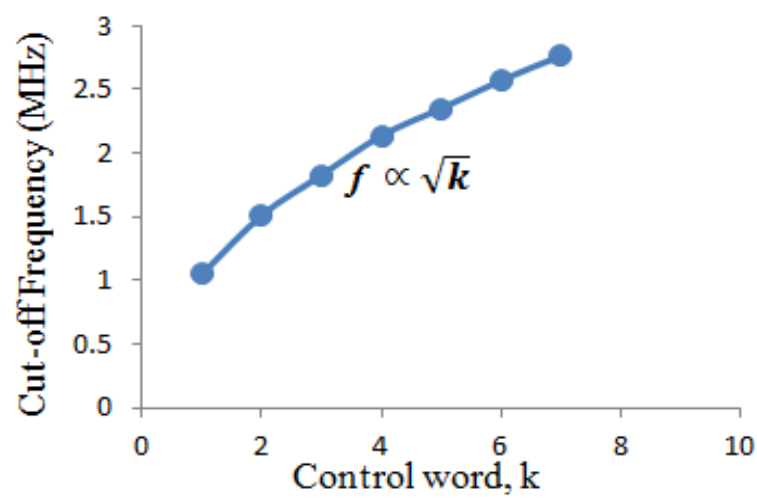

Fig. 10(a): Variation of cut-off Frequency of LPF with digital control word

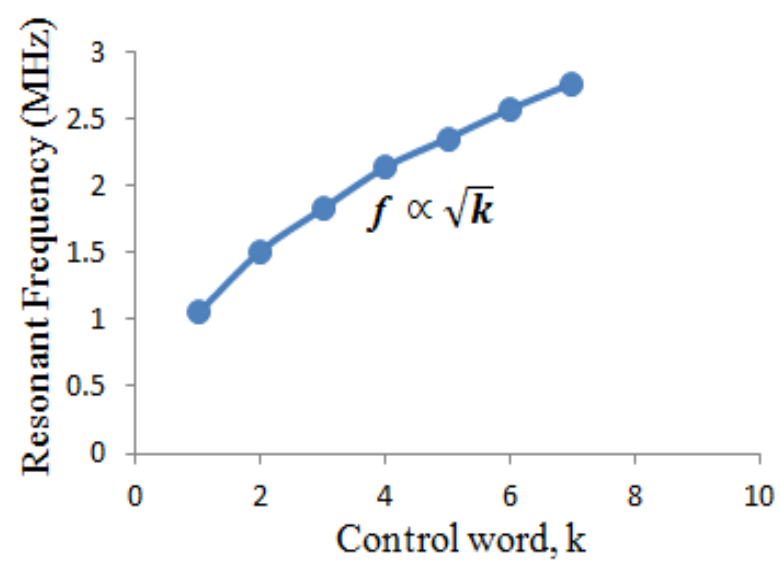

Fig. 10(b). Variation of cut-off Frequency of BPF with digital control word

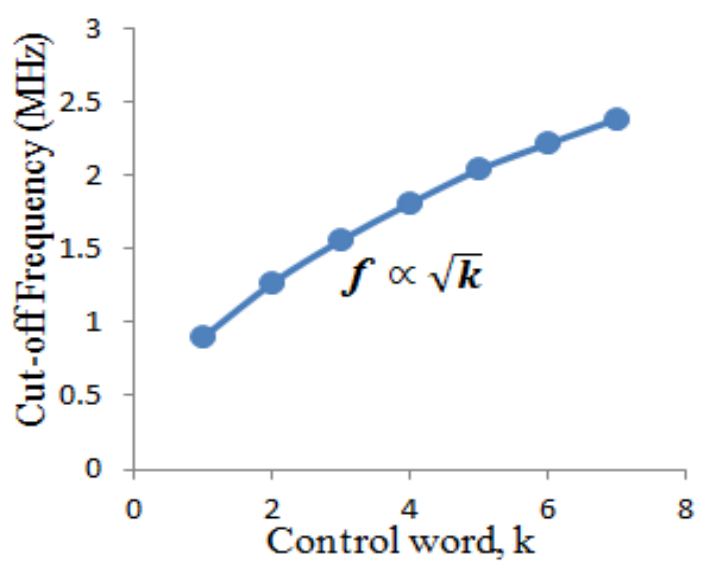

Fig. 10(c): Variation of cut-off Frequency of HPF with digital control word
Table 2. Variation in cut-off frequencies with the control

\begin{tabular}{|c|c|c|c|}
\hline $\begin{array}{c}\text { Control } \\
\text { word, } \mathbf{k}\end{array}$ & $\begin{array}{c}\text { Cut-off } \\
\text { frequency of } \\
\text { LPF (MHz) }\end{array}$ & $\begin{array}{c}\text { Resonant } \\
\text { frequency of } \\
\text { BPF (MHz) }\end{array}$ & $\begin{array}{c}\text { Cut-off } \\
\text { frequency of } \\
\text { HPF (MHz) }\end{array}$ \\
\hline 1 & 0.901 & 0.901 & 0.901 \\
\hline 2 & 1.269 & 1.269 & 1.269 \\
\hline 3 & 1.561 & 1.561 & 1.561 \\
\hline 4 & 1.812 & 1.812 & 1.812 \\
\hline 5 & 2.041 & 2.041 & 2.041 \\
\hline 6 & 2.216 & 2.216 & 2.216 \\
\hline 7 & 2.385 & 2.385 & 2.385 \\
\hline
\end{tabular}

\section{CONCLUSIONS}

In this paper, a digitally controlled voltage-mode multifunctional biquadratic filter based on single DVCC was presented. Digital control was achieved by the variation of 3 bit digital control word using a Current summing network (transistor arrays). Digitally controlled low-pass, high-pass and band-pass filter responses were obtained. PSPICE simulations were carried out to verify the working of the digitally controlled multifunctional biquadratic filter. It is observed that the cut-off frequency varies from $1.267 \mathrm{MHz}$ to $3.072 \mathrm{MHz}$ for low-pass filter, $901 \mathrm{kHz}$ to $2.385 \mathrm{MHz}$ for high-pass filter, $1.051 \mathrm{MHz}$ to $2.765 \mathrm{MHz}$ for band-pass filter by varying the digital control word from $\left[\begin{array}{lll}0 & 0 & 1\end{array}\right]$ to $\left[\begin{array}{lll}1 & 1 & 1\end{array}\right]$ (recorded in Table 2), without changing the value of any of the passive components i.e. resistors and capacitors being used in the design. The significant feature of this circuit is that it uses a single DVCC block and minimum number of passive components. The digital controls for the cut-off frequency of the respective filters are in full conformity with the mathematical calculations.

\section{REFERENCES}

[1] H. Hakan Kuntman. "New Advances and Possibilities in Active Circuit Design." in Proc. 10th International Conference on Development and Application Systems, 2010, pp. 9-18.

[2] B. Wilson, "Recent developments in current conveyors and current-mode circuits." Circuits, Devices and Systems, IEE Proceedings G, vol. 137, issue. 2, pp. 6377, Apr.1990.

[3] A.S. Sedra, K.C. Smith. "A second generation current conveyor and its applications". IEEE Transactions on circuit theory, vol. 17, pp.132-134, Feb. 1970.

[4] W. Chiu, S. I. Liu, H. W. Tsao, J. J. Chen. "CMOS differential difference current conveyors and their applications." IEE Proceedings-Circuits, Devices and Systems, vol. 143, issue. 2, pp. 91-96, Apr. 1996.

[5] H.O. Elwan, A. M. Soliman. "Novel CMOS differential voltage current conveyor and its applications." IEE Proceedings-Circuits, Devices and Systems, vol. 144, issue. 3, pp. 195-200, Jun. 1997.

[6] H. Sedef, C. Acar. "A new floating inductor circuit using differential voltage current conveyors." Frequenz , vol. 54, issue. .5-6, pp. 123-125, 2000. 
[7] H. Sedef, C. Acar. "A new floating FDNR circuit using differential voltage current conveyors". Int. J. Electronics and Communications, AEÜ, vol. 54, pp.297301, 2000.

[8] S. S. Gupta and R. Senani, "Grounded-capacitor currentmode SRCO: novel application of DVCC", Electronics Letters, vol. 36, issue. 3, pp. 195-196, 2000.

[9] T. Dostal, D. Biolek, K. Vrba. "Adjoint voltage-current mode transformation for circuits based on modern current conveyors." Devices, Circuits and Systems, Proceedings of the Fourth IEEE International Caracas Conference, 2002, pp. T034-1.

[10] S. Minaei,C. Temizyürek. "Dual input all-pass filter using DVCC." International Symposium on Signals, Circuits \& Systems (SCS), vol. 2, pp. 477-480, Jul. 2003.
[11] H. P. Chen, W. Chien, and G.W. Huang. "Single DVCCBased Voltage-Mode Multifunction Biquadratic Filter." The International Multi-Conference on Complexity, Informatics and Cybernetics (IMCIC), 2010.

[12] W. Tangsrirat , O. Chaannumsin. "Voltage -mode multifunctional biquadratic filter using single DVCC and minimum number of passive elements". Indian Journal of Pure and Applied Physics, vol. 49, pp.703-707, Oct. 2011.

[13] S. A. Mahmoud, M.A. Hashiesh. and A.M. Soliman. "Low-voltage digitally controlled fully differential current conveyor." Circuits and Systems I: Regular Papers, IEEE Transactions, VOL. 52, issue. 10, pp.2055-2064, Oct. 2005. 